\title{
A Sociolinguística Educacional na formação do professor: crenças e atitudes linguísticas de acadêmicos de Letras
}

\author{
The Educational Sociolinguistics in teacher training: beliefs and linguistic attitudes \\ of academics of Letras
}

\author{
Vera Maria Ramos Pinto* \\ Universidade Estadual do Norte do Paraná \\ Jacarezinho, Paraná, Brasil. \\ Thiago Leonardo Ribeiro ${ }^{* *}$ \\ Universidade Estadual de Londrina \\ Londrina, Paraná, Brasil
}

\begin{abstract}
Resumo: Os documentos oficiais de ensino, como os Parâmetros Curriculares Nacionais (PCN/1998), orientam que o ensino de língua portuguesa nas salas de aula deve levar em consideração a abordagem da variação linguística juntamente com o ensino da gramática normativa. Desse modo, é necessário que os professores de Língua Portuguesa (LP) tenham consciência da diversidade da nossa língua e conheçam a realidade linguística dos seus alunos, para não possibilitar a eles apenas o conhecimento da norma padrão. Diante disso, com base em estudos teórico-metodológicos de Bortoni-Ricardo (2004, 2005), Cyranka (2007, 2014, 2015, 2016), Coelho et al (2010, 2015), Faraco (2008, 2015), Lambert e Lambert (1972), Gómez Molina (1987), Santos (1996), entre outros, neste artigo, apresentamos as crenças e atitudes linguísticas de acadêmicos que ingressam nos cursos de Letras sobre a visão do ensino de Língua Portuguesa, sobretudo, no que diz respeito à abordagem da variação linguística nas aulas de LP, com base na pesquisa de doutorado de Pinto (2018), cuja tese defendida é a de que, na formação inicial do docente de Letras, além do conhecimento teóricocientífico e metodológico sobre e como lidar com a variação linguística no contexto escolar, é preciso que os professores sejam mediadores na construção da consciência linguística desses futuros docentes.
\end{abstract}

Palavras-chave: Formação inicial. Acadêmicos de Letras. Crenças e atitudes linguísticas. Variação linguística. Língua Portuguesa.

Abstract: Official teaching documents, such as the National Curriculum Parameters (PCN / 1998), point out that Portuguese language teaching in classrooms must take into account the approach of linguistic variation together with the teaching of normative grammar. Thus, it is necessary that teachers of Portuguese Language (LP) are aware of the diversity of our language and know the linguistic reality of their students, so as not to allow them only the knowledge of the standard norm. Based on theoretical-methodological studies by BortoniRicardo (2004, 2005), Cyranka (2007, 2014, 2015, 2016), Coelho et al (2010, 2015), Faraco (2008,2015), Lambert and Lambert (1972), Gómez Molina (1987), Santos (1996), among others, in this article, we present the linguistic beliefs and attitudes of academics who enter the courses of Letras on the vision of Portuguese language teaching, especially with regard to approach to linguistic variation in LP classes, based on Pinto's doctoral research (2018), whose thesis is defended that, in the initial formation of the teacher of Letras, besides theoretical-scientific and methodological knowledge about and how to deal with the linguistic variation in the school context, it is necessary that the teachers are mediators in the construction of the linguistic conscience of these future teachers.

Keywords: Initial formation. Academics of Letras. Beliefs and linguistic attitudes. Linguistic variation. Portuguese language.

\footnotetext{
* Doutora em Estudos da Linguagem, Professora Adjunta na Universidade Estadual do Norte do Paraná - UENP/ Campus Jacarezinho. Paraná. Brasil. Líder do Grupo de Pesquisa Leitura e Ensino - UENP/CJ. E-mail: veramaria@uenp.edu.br ** Doutorando em Estudos da Linguagem - PPGEL/Universidade Estadual de Londrina - UEL. Paraná. Brasil. Integrante do Grupo de Pesquisa Leitura e Ensino - UENP/CJ. E-mail: thiagoleonardoribeiro@gmail.com
} 


\section{INTRODUÇÃO}

A Sociolinguística tem sido uma área de ampla investigação nos últimos anos, cujos resultados de pesquisas e estudos refletem “[...] não apenas nas descrições das línguas enquanto sistemas, mas também nas decisões políticas e educacionais exigidas pelas inúmeras questões que a diversidade linguística vem suscitando no mundo moderno" (MONTEIRO, 2000, p. 9).

Diante disso, podemos assegurar que são muitas as contribuições que os estudos sociolinguísticos dão ao ensino de uma língua, principalmente, os estudos e pesquisas advindos da corrente variacionista, cujo maior expoente é Willian Labov ([1972] 2008).

O impacto do trabalho de Labov sobre os estudos da linguagem é amplamente reconhecido, principalmente, no Brasil. Bagno, como tradutor da obra Sociolinguistic Patterns (1972), Padrões sociolinguisticos em português brasileiro, na apresentação da edição, afirma:

É inegável que a sociolinguística variacionista tem fornecido suporte empírico para o combate às construções ideológicas que se apoiam nas diferenças linguísticas como pretexto para suas políticas de discriminação e de exclusão social. A militância de Labov na defesa do que ele chamou, em artigo clássico de 1966, de 'A lógica do inglês não padrão' - a defesa do inglês dos negros norte-americanos como uma língua dotada de regras perfeitamente demonstráveis e coerentemente seguidas por seus falantes - tem inspirado a luta daqueles que reconhecem no uso da língua o mais importante elemento da cultura e da vida em sociedade, sendo, portanto, um constituinte essencial da consolidação da cidadania e do convívio democrático (BAGNO, 2008, p. 9-10).

Corroborando a assertiva do autor, Cyranka (2015, p. 32) menciona:

Para se constituir pela linguagem, é preciso que o homem tenha a palavra que lhe seja permitido se expressar, mesmo que seja no seu dialeto desprestigiado. Isso aponta para os novos caminhos abertos pela sociolinguística já na década de 1960. De fato, é com Labov ([1972] 2008) que a contraparte social da linguagem, isto é, os valores culturais da comunidade do falante, passam a fazer parte dessas reflexões. Somente a partir da criação da nova ciência sociolinguística, que trouxe para os estudos da fala essa contraparte social e ideológica, tornou-se possível compreender os fenômenos da variação e da mudança e suas repercussões nos julgamentos que membros de qualquer comunidade de fala costumam fazer sobre os usos linguísticos.

Diante das considerações dos autores, é possível observarmos que os estudos sociolinguísticos labovianos influenciaram também o contexto educacional. "O reconhecimento da variação linguística em sua estreita correlação com a heterogeneidade social tem redirecionado as concepções de língua e de ensino de língua nas diretrizes oficiais e na prática pedagógica em sala de aula" (BAGNO, 2008, p.10).

Sendo assim, no contexto escolar brasileiro, foi com a publicação dos Parâmetros Curriculares Nacionais (PCN, 1988) que é reconhecida a importância da abordagem da variação linguística nas aulas de Língua Portuguesa. Segundo esses documentos de ensino, 
as variedades linguísticas devem fazer parte dos conteúdos programáticos de Língua Portuguesa nas escolas de ensino fundamental e médio e "[...] o respeito à diversidade é o principal eixo da proposta" (BRASIL, 1998, p. 4).

Nos PCN, preconiza-se uma nova postura para o ensino de Língua Portuguesa que vai para além do ensino da gramática normativa, com o reconhecimento das variedades linguísticas. Nesse cenário, a Sociolinguística Educacional, inaugurada por Bortoni-Ricardo (2004), começa a ganhar espaço, principalmente, com o desenvolvimento das pesquisas que buscaram compor um retrato bastante fiel da nossa realidade linguística, com especial interesse na descrição do Português Brasileiro (PB).

Com a divulgação dos resultados dessas pesquisas para um público maior, na tentativa de transformar esses resultados em instrumental pedagógico capaz de interferir nas práticas de educação sociolinguística, isto é, nas formas de ensinar a língua portuguesa nas escolas, a Sociolinguística Educacional, então, é estabelecida como uma subárea da Sociolinguística que veio para "denominar todas as propostas e pesquisas sociolinguísticas que tenham por objetivo contribuir para o aperfeiçoamento do processo educacional" (BORTONI-RICARDO, 2005, p. 128).

Isso tudo nos mostra que existem muitas pesquisas e estudos sobre o português brasileiro (PB), sobre a diversidade linguística do Brasil, sobre a Sociolinguística Variacionista e a Sociolinguística Educacional. Entretanto sabemos que essa concepção de ensino, pautada pelo estudo da variação linguística concomitante ao ensino da norma padrão, não chega de forma efetiva aos cursos de formação docente inicial de Letras.

Sobre essa situação, Bortoni-Ricardo (2010, p. 73) afirma: "É lamentável que isso ocorra, pois os trabalhos de base sociolinguística, com viés educacional, podem contribuir muito na solução dos problemas educacionais brasileiros. Mas, para isso, é preciso que esses trabalhos de fato atinjam o seu principal público leitor, que é o professor em formação ou em atividade".

Para que isso aconteça, portanto, Bortoni-Ricardo (2016, s.p.) assevera que necessário se faz desenvolver um processo sistemático de reflexão e conscientização sobre a interferência dos fenômenos de variação linguística nos diversos usos da língua portuguesa dentro e fora da sala de aula.

Entretanto, a autora pondera que é preciso ter em mente que isso não ocorre de um dia para o outro e que não pode ser visto como se fosse fruto de uma simples adesão por parte dos docentes, mas de um processo contínuo e sistemático de trabalho e reflexão sobre os aspectos formais da língua, seus gêneros, seus usos, seu contexto, sua história e seus falantes, bem como de uma política de formação de professores planejada desde sua fase inicial até os estágios mais avançados da formação continuada, que objetive subsidiar as práticas de ensino da Língua Portuguesa numa visão plural do conhecimento científico.

Por isso, defendemos que, na formação inicial do docente de Letras, é preciso dar aos graduandos, além do conhecimento teórico-científico e metodológico sobre e como lidar com a variação linguística no contexto escolar, é preciso que nós, professores, sejamos mediadores na construção da consciência linguística desses futuros professores.

Desta feita, é possível que compreendam que toda essa diversidade linguística deve ser trabalhada em conjunto com o ensino da gramática tradicional nas salas de aula do 
ensino fundamental e médio, apesar de sabermos que a maioria dos estudantes, ao ingressar nos cursos de Letras, chega com a crença de que ensinar a língua portuguesa é ensinar a norma padrão para poderem falar e escrever bem.

Essa realidade pode ser comprovada com vários estudos e pesquisas empreendidas sobre crenças e atitudes linguísticas de professores e alunos com relação ao ensino de língua portuguesa, ao preconceito linguístico, à abordagem da variação linguística no contexto escolar.

Sendo assim, neste artigo, objetivamos apresentar resultado de pesquisa empreendida com acadêmicos dos $1^{\text {os }}$ anos dos cursos de Letras, da Universidade Estadual do Norte do Paraná (UENP), Campus Jacarezinho, que investigou e avaliou as crenças e atitudes linguísticas sobre a visão do ensino de Língua Portuguesa desses estudantes de Letras, sobretudo, no que diz respeito à abordagem da variação linguística no contexto escolar, com base na tese de doutorado de Pinto (2018).

\section{PRESSUPOSTOS TEÓRICOS}

O constructo teórico da pesquisa que ora apresentamos é alicerçado, principalmente, nos princípios da Sociolinguística Variacionista, liderada pelos estudos de Labov ([1972] 2008) e da Sociolinguística Educacional, com base em Bortoni-Ricardo (2004, 2005); Bagno (2007); Faraco (2008, 2015), como também nos estudos sobre crenças e atitudes linguísticas de Lambert e Lambert (1972); Gómez Molina (1987); Santos (1996); Cyranka (2007, 2014), Corbari (2012), dentre outros.

Faraco (2015, p. 28) ressalta que vivemos num ambiente sociolinguístico heterogêneo, em que observamos as mais diferentes variedades da língua, como as expressões linguísticas usadas pelos idosos, jovens e crianças; as variedades cultas do rádio e televisão; as variedades da igreja, local de trabalho, clubes sociais etc.

O linguista paranaense, valendo-se dos apontamentos de Lucchesi (1994), mostra que essa complexidade de normas é decorrente do "fato de o português no Brasil não ser apenas heterogêneo e variável, mas também plural e polarizado" (FARACO, 2016, p. 363).

Isto posto, se a experiência de vida é sociolinguisticamente heterogênea, aproveitamos o questionamento proferido por Faraco (2015, p. 28): “por que deveria a escola ignorar a realidade e perseguir a quimera de ser sociolinguisticamente homogênea e esterilizada?".

Com o propósito de, ao menos mudar esse quadro no contexto escolar, conforme já mencionado na introdução deste artigo, surge, no Brasil, a Sociolinguística Educacional (BORTONI-RICARDO, 2004) cujos estudos são pautados nas relações entre linguagem e ensino.

Cyranka, corroborando os estudos e postulações de Bortoni-Ricardo, em trabalho com outros pesquisadores, apregoa que

Cabe à escola, isso sim, levar os alunos a ampliarem sua competência linguística, tornandose capazes de transitar pelos contínuos chegando, quando lhes convier, a situarem-se na 
extremidade direita de cada um deles, para construírem expressões linguísticas próprias da fala urbana, monitorada, em eventos de letramento (CYRANKA et al, 2014, p. 79).

Sendo assim, entendemos que, o que a sociedade encara como erro na fala das pessoas, a Sociolinguística considera uma questão de inadequação da forma utilizada ao que se espera ouvir. Portanto, a Sociolinguística analisa a variante empregada, avalia o prestígio a ela associado e mostra em que circunstâncias aquela variante é adequada, considerando-se as normas vigentes.

\subsection{OS DOCUMENTOS OFICIAIS DE ENSINO, A SOCIOLINGUÍSTICA EDUCACIONAL E A VARIAÇÃO LINGUÍSTICA}

A partir dos anos 1980 ocorre uma grande transformação na concepção de língua na escola brasileira, "com a publicação, dentre outros, de Subsídios à proposta curricular de Lingua Portuguesa para o $2^{\circ}$ Grau, documento elaborado por Ataliba Castilho, Roberto Camacho, Maurício Gnerre et alii para a Secretaria da Educação do Estado de São Paulo” (DIAS, 2011, p. 24).

Nas palavras da autora

Esse texto, fundamentado na Sociolinguística, traz a heterogeneidade e a diversidade linguística para dentro do ensino de Língua Portuguesa. A partir daí, ensinar língua na escola passa a exigir uma visão crítica sobre a gramática, uma reflexão sobre: as diferenças entre o oral e o escrito; os diferentes registros e modalidades de uso da língua (DIAS, 2011, p. 24).

Ainda, na década de 80, no ano de 1986, foi nomeada pelo então Presidente José Sarney, a Comissão Nacional para o Aperfeiçoamento do Ensino Aprendizado da Língua Portuguesa, por meio do Decreto n. 91.372, de 26 de junho de 1985, do Ministério da Educação.

Entretanto, é sabido que foi com a publicação dos Parâmetros Curriculares Nacionais (PCN, 1998) que se reconhece a importância da abordagem da variação linguística nas aulas de Língua Portuguesa.

Nos PCN (1998), observamos uma nova postura para o ensino de Língua Portuguesa que vai para além do ensino da gramática normativa, com o reconhecimento, conforme já mencionado, das variedades linguísticas.

Não se pode mais insistir na ideia de que o modelo de correção estabelecido pela gramática tradicional seja o nível padrão de língua ou que corresponda à variedade linguística de prestígio. Há, isso sim, muito preconceito decorrente do valor atribuído às variedades padrão e ao estigma associado às variedades não-padrão, consideradas inferiores ou erradas pela gramática. Essas diferenças não são imediatamente reconhecidas e, quando são, não são objeto de avaliação negativa (BRASIL, 1998, p. 31).

Sendo assim, esse documento oficial de ensino postula: 
Para cumprir bem a função de ensinar a escrita e a língua padrão, a escola precisa livrar-se de vários mitos: o de que existe uma forma "correta" de falar, o de que a fala de uma região é melhor do que a de outras, o de que a fala "correta" é a que se aproxima da língua escrita, o de que o brasileiro fala mal o português, o de que o português é uma língua difícil, o de que é preciso "consertar" a fala do aluno para evitar que ele escreva errado (BRASIL, 1998, p.31).

Com as preconizações dos PCN (1998) para uma nova concepção de ensino de LP, que leve em consideração todas as variedades da língua brasileira, que discuta e reflita com os alunos a realidade linguística do nosso país, a Sociolinguística Educacional se estabelece, principalmente, com o desenvolvimento das pesquisas que buscaram compor um retrato bastante fiel da nossa realidade linguística, com especial interesse na descrição do português brasileiro (PB).

Cyranka (2016, p.169), sobre a educação sociolinguística, alega

[...] A Sociolinguística Educacional propõe que se leve para as salas de aula a discussão sobre a variação linguística, orientando os alunos a reconhecerem as diferenças dialetais e, mais importante, a compreenderem que essas diferenças são normais, legítimas e que devem ser consideradas na seleção das estruturas a serem utilizadas a depender das condições de produção, isto é, das necessidades do leitor/escritor, falante/interlocutor, a partir do contexto em que se encontra. Desse modo, o conceito de 'certo/errado' em linguagem é substituído pelo de 'adequado/inadequado', o que predispõe os alunos ao desejo de ampliarem a competência comunicativa que já possuem, construindo crenças positivas sobre o conhecimento que têm de sua língua, no caso, a língua portuguesa.

Para Bortoni-Ricardo e Freitas (2009, p. 220), a Sociolinguística Educacional busca respostas para questionamentos educacionais dentro da própria escola. "Com isso, essa vertente da Sociolinguística, envolve-se em temas consideravelmente mais amplos que se inserem no contexto social maior, [...]. E é para esse contexto que a escola deve preparar o indivíduo".

\subsection{A PEDAGOGIA DA VARIAÇÃO LINGUÍSTICA E A PEDAGOGIA CULTURALMENTE SENSÍVEL}

A palavra pedagogia remete-nos à educação, ao ensino. Como afirma Libâneo (1998, p. 30), Pedagogia é "o campo do conhecimento que se ocupa do estudo sistemático da educação, isto é, do ato educativo, da prática educativa concreta que se realiza na sociedade como um dos ingredientes básicos da configuração da atividade humana".

Sendo assim, podemos entender a Pedagogia da variação linguística como práticas educativas, práticas de ensino da Língua Portuguesa, que levam em consideração a abordagem da variação linguística no contexto escolar, todas as variedades da língua, desde a norma padrão às normas de menor prestígio social, a norma popular ou vernacular.

Faraco e Zilles (2015, p. 7) argumentam que "a variação linguística é uma realidade que, embora razoavelmente bem estudada pela Sociolinguística, pela Dialetologia e pela Linguística Histórica, provoca, ainda, reações sociais muito negativas". 
Isso demonstra que a língua continua sendo "forte elemento de discriminação social, seja no próprio contexto escolar, seja em outros contextos sociais, como no acesso ao emprego e aos serviços públicos em geral, a exemplo dos serviços de saúde" (FARACO e ZILLES, 2015, p. 8).

A grande questão, ou até mesmo um grande desafio, é saber como abordá-la de forma pedagógica. Assim, os autores questionam:

Como desenvolver uma pedagogia da variação linguística no sistema escolar de uma sociedade que ainda não reconheceu sua complexa cara linguística e, como resultado da profunda divisão socioeconômica que caracterizou historicamente sua formação (uma sociedade que foi, por trezentos anos escravocrata), ainda discrimina, fortemente pela língua, os grupos socioeconômicos que recebem as menores parcelas de renda nacional (FARACO e ZILLES, 2015, p.8).

Por isso, necessário se faz desenvolver uma nova atitude do professor de língua portuguesa. Para Cyranka (2015, p. 35), essa nova postura implica:

[...] lembrar, antes de tudo, de que não vai "ensinar" o que os alunos já sabem, ele não vai ensiná-los a falar português. O que cabe ao professor é, simplesmente, considerando as experiências reais de seus alunos quanto ao uso da língua portuguesa, considerando a variedade linguística que eles utilizam e sua capacidade de nela se expressarem, conduzi-los nas atividades pedagógicas de ampliação de sua competência comunicativa.

Já Bortoni-Ricardo defende que lidar com a miscigenação cultural, linguística e social nas salas de aula torna-se um grande desafio. Para propor aos alunos com esse perfil um programa de desenvolvimento de habilidades no uso da língua, tanto na modalidade oral quanto na modalidade escrita, a fim de torná-los competentes, no uso das variedades prestigiadas, "é preciso o apoio de uma pedagogia, cunhada por Erickson (1987), de pedagogia culturalmente sensivel (culturally responsive pedagogy)" (BORTONI-RICARDO, 2005, p. 118).

A autora traduz a definição de Erickson para Pedagogia culturalmente sensivel como:

[...] um tipo de esforço especial, empreendido pela escola, a fim de reduzir os problemas de comunicação entre professores e alunos e desenvolver confiança e impedir a gênese de conflito que se move rapidamente para além das dificuldades de comunicação, transformando-se em lutas amargas de trocas de identidade negativas entre alguns alunos e seus professores (BORTONI-RICARDO, 2005, p.118).

Para que essa pedagogia aconteça, é necessário que os “[...] professores conheçam seu aluno, saibam a que comunidade de fala ele pertence, que valores culturais perpassam suas experiências, que práticas de letramento têm vivenciado. Tudo isso significa ter em mãos dados etnográficos que possam iluminar o caminho a ser percorrido" (CYRANKA, 2015, p. 35).

Cabe, portanto, ao ensino de língua portuguesa na educação básica, do ensino fundamental ao médio, oportunizar aos alunos a conscientização de que a aquisição linguística, consoante Mattos e Silva (2004, p. 35-36), “[...] é um processo contínuo de 
conhecimento e de reconhecimento da multiplicidade de manifestações possíveis de sua língua - desde os extremos dos usos populares aos extremos dos usos acadêmicos, perpassando por eles as variedades regionais".

Se os professores assim fizerem, com certeza, poderão dar a esses alunos o poder que todos têm o direito de ter sobre a língua materna. Entretanto, podemos dizer que o ponto nevrálgico do tema "variação linguística e ensino" recai na aceitação, por parte tanto dos alunos quantos dos professores, das propostas de se trabalhar a variação linguística, as variedades linguísticas, em sala de aula.

Ainda, de acordo com Mattos e Silva (2004), para que o ensino da variação linguística realmente seja efetivado nas escolas é preciso primeiramente que o professor esteja preparado. Por isso, defendemos que a conscientização sobre a importância da abordagem da variação linguística nas aulas de Língua Portuguesa, concomitante com o ensino da norma padrão, deve começar na formação docente inicial, na graduação (PINTO, 2018).

Confirmando nossa proposição, Coelho et al (2010, p. 153), afirmam que "[...] é preciso ter um embasamento teórico consistente acerca da linguagem em seu funcionamento social para poder atuar, de forma competente, na orientação da aprendizagem e na formação contínua do aluno-cidadão. E esse embasamento é adquirido na formação inicial dos cursos de Letras".

“O domínio dos postulados sociolinguísticos básicos (e seus desdobramentos e implicações) é o mínimo que se espera do professor de língua portuguesa nos dias atuais" (COELHO et al, 2010, p. 154).

Com base na pesquisa realizada por Pinto (2018) com os acadêmicos dos $1^{\text {os }}$ anos dos cursos de Letras da UENP/CJ, foi-nos possível constatar que a maioria deles quando ingressa para o curso de Letras tem como objetivo aprender a gramática da língua portuguesa ou a língua estrangeira do curso escolhido. No caso dos cursos de letras da UENP, as línguas estrangeiras espanhol ou inglês. Assim, buscamos, em nossa tese de doutorado intervir para tentar mudar essa realidade.

Como o projeto de intervenção não é o foco deste artigo, detemo-nos apenas à exposição dos resultados da pesquisa que investigou e avaliou as crenças e atitudes linguísticas dos acadêmicos do $1^{\circ}$ ano dos cursos de Letras/Espanhol e Letras/Inglês da $\mathrm{UENP} / \mathrm{CJ}$.

Antes, porém, de discorremos sobre a análise e os resultados da pesquisa, apresentamos uma abordagem sucinta sobre crenças e atitudes linguísticas e sobre a metodologia usada para a coleta dos dados, via questionário.

\subsection{CRENÇAS E ATITUDES LINGUÍSTICAS}

Para a Sociolinguística, os estudos nos campos de crenças e atitudes são de grande relevância, pois buscam entender o fenômeno da variação a partir da consciência que o usuário da língua tem diante do seu idioma ou da sua variante.

Neste contexto, Aguilera (2008, p. 106) afirma: 
Um traço definidor da identidade do grupo (etnia, povo) é a variedade linguística assumida e, desse modo, qualquer atitude em relação aos grupos com determinada identidade pode, na realidade, ser uma reação às variedades usadas por esse grupo ou aos indivíduos usuários dessa variedade, uma vez que normas e marcas culturais dos falantes se transmitem ou se sedimentam por meio da língua, atualizada na fala de cada indivíduo.

Sabendo que a língua é um fato social e, como tal, é inerente a todos os seres humanos, Carraro (2016, p. 9) afirma que "[...] é por meio dela que nos moldamos e nos constituímos social e individualmente, (re)construindo, assim, nossa identidade".

Corbari (2012, p. 115) complementa: "É a língua que simboliza os limites que separam o 'nós' e os 'outros', uma vez que a língua que falamos identifica nossa origem, nossa história, nossa cultura, o grupo a que pertencemos, compondo a(s) nossa(s) identidade(s)".

Considerando que a língua faz parte da vida humana, Corbari (2012, p. 115) aponta que "[...] é comum que quem a utiliza, sendo falante de uma ou várias línguas, formule opiniões e reaja sobre sua própria língua e também sobre a dos outros".

Também, levando-se em consideração que as pessoas categorizam a língua em escalas de valores e, por isso, por intermédio dela, pode-se explicar a vida de uma sociedade, é correto, segundo Carraro (2016), pensar que existem determinados grupos que se reconhecem por meio da língua que utilizam e que possuem crenças sobre a língua que falam e, consequentemente, refletem essas crenças em suas atitudes.

Barcelos (2006, p. 18) define crenças como

[...] uma forma de pensamento, construções da realidade, maneiras de ver e perceber o mundo e seus fenômenos, co-construídas em nossas experiências resultantes de um processo interativo de interpretação e (re)significação. Como tal, crenças são sociais (mas também individuais), dinâmicas, contextuais e paradoxais.

As crenças não são, pois, estáticas. Estão em constante construção e podem ser modificadas com o passar do tempo. São construídas ideológica e socialmente, a partir de nossas experiências individuais ou em sociedade. Portanto, todos acreditam em alguma coisa, têm convicções, têm um modo de pensar e, consequentemente, de agir.

Todos nós temos e tomamos atitudes. Lambert e Lambert (1972), estudiosos da Psicologia Social, definem atitude como

[...] uma maneira organizada e coerente de pensar, sentir e reagir em relação a pessoas, grupos, questões sociais ou, mais genericamente, a qualquer acontecimento ocorrido em nosso meio circundante. Seus componentes essenciais são os pensamentos e as crenças, os sentimentos (ou emoções) e as tendências para reagir (LAMBERT; LAMBERT, 1972, p. 78).

Ainda, para eles:

As atitudes desempenham uma função essencial na determinação do nosso comportamento; por exemplo, afetam nossos julgamentos e percepções sobre outros, ajudam a determinar os grupos com que nos associamos, as profissões que finalmente escolhemos e até as filosofias à sombra das quais vivemos (LAMBERT; LAMBERT, 1972, p. 83). 
Vale mencionar que até o final da década de 60, a Psicologia Social não demonstrava interesse pelo "[...] aspecto sociocultural da linguagem nem por questões sociolinguísticas, servindo-se da linguagem somente como um instrumento para obter dados" (SILVA e BOTASSINI, 2015, p.13).

Foi devido à preocupação de Wallace Lambert ([1967] 2003), considerado o precursor dos estudos sobre atitudes linguísticas, com os aspectos social, ideológico e cultural da linguagem, a partir da publicação, em 1967, do artigo A Social Psychology of Bilingualism, no Journal of Social Issues, que o tema 'atitude' passa a interessar não só aos psicólogos sociais, mas também aos linguistas especialmente àqueles que se dedicavam à área da Sociolinguística, sobretudo em pesquisas voltadas para o assunto de línguas e dialetos em contato.

Gómez Molina aponta que a atitude linguística

[...] atua de forma muito ativa nas mudanças de ou alternância de línguas; é um fator decisivo, junto à consciência lingüística, na explicação da competência dos falantes; permite ao pesquisador aproximar-se do conhecimento das reações subjetivas diante da língua e/ou línguas que usam os falantes; e influi na aquisição de segundas línguas (GÓMEZ MOLINA, 1987, p. 25) ${ }^{1}$.

Para Cyranka (2007, p. 20), o conceito de atitudes linguísticas está relacionado, imanentemente, à avaliação linguística (campo estudado pela Sociolinguística), isto é, "[...] ao exame dos julgamentos dos falantes em relação à língua ou ao dialeto utilizado por seu interlocutor, estando subentendidas aí as mudanças implementadas, ou em implementação na língua, em relação à variedade considerada padrão".

O que pensam, sentem e como reagem os falantes expostos aos estímulos linguísticos que lhes são apresentados são os componentes das atitudes dos falantes (CYRANKA, 2007, p. 20).

Um sujeito, portanto, terá sempre uma atitude positiva, negativa ou neutra em relação a qualquer objeto ou conceito a ser avaliado. Crenças e atitudes se relacionam.

Para Santos, essa relação é perceptível a partir da mudança de atitudes de indivíduos que tiveram suas crenças mudadas, ou seja, novas crenças geram novas atitudes:

[...] crenças e atitudes aparecem inter-relacionadas, e isto, como já tem sido demonstrado, de forma sensível e dinâmica: a mudança em uma parte do sistema acarreta mudança em outra parte. Várias pesquisas produziram evidências de que a atitude de um indivíduo pode ser mudada se forem mudadas suas crenças sobre o objeto (SANTOS, 1996, p. 15).

A fim de esclarecer a relação entre crenças e atitudes, o autor cita o exemplo da manifestação de crença com um enunciado bastante comum entre os alunos, nas aulas de

\footnotetext{
${ }^{1}$ [...] actúa de forma muy activa en los cambios de código o alternancia de lenguas; es un factor decisivo, junto a la conciencia lingüística, en la explicación de la competencia de los hablantes; permite aproximarnos al conocimiento de las reacciones subjetivas ante la lengua o lenguas que usan los hablantes; influye en la adquisición de segundas lenguas, etc.
} 
Língua Portuguesa: "o português é muito difícil”, argumentando que alunos e professores podem ter atitudes opostas quanto a isso.

Enquanto os alunos rejeitam o objeto, (isto é, a aprendizagem da disciplina português) por causa dos obstáculos, muitas vezes, oriundos de regras e exceções que consideram difíceis, complexas, os professores podem ter uma atitude positiva em relação à disciplina, justamente por se sentirem valorizados, já que são capazes de dominar o conhecimento de um objeto tão complexo.

Com isso, é possível observar que crenças e atitudes estão inseridas nos processos educacionais da língua. Embora a escola esteja "[...] a serviço dos interesses dos grupos dominantes dentro de uma sociedade complexa" (SANTOS, 1996, p. 18), e que, para esses grupos, é importante a manutenção de sua identidade, e uma das marcas de seu status é a variedade da língua que usam. Deve-se acreditar que crenças e atitudes são um comportamento individual e, uma vez adquiridas, são passíveis de modificação.

Portanto, há grandes possibilidades de nos valermos de novas crenças que combatam as velhas crenças e atitudes. A escola, como transmissora dessa variedade padrão, firmada em velhas crenças e atitudes, acaba por preservar o valor distintivo dessa variedade da língua e garantir-lhe a continuidade.

Não é esse, porém, o papel da escola. Uma das suas funções é erradicar o estigma, a discriminação pela língua e valorizar a pluralidade linguística brasileira, articulando essa diversidade com o ensino de todas as normas, da padrão, da culta e da vernacular.

Assim, é preciso que novas crenças sejam formadas na concepção de ensino da língua portuguesa, para que novas atitudes com relação ao ensino possam ser tomadas pela escola e pelos professores.

Um dos caminhos é a conscientização sobre a heterogeneidade linguística do nosso país, sobre a necessidade da abordagem da variação linguística no contexto escolar. E essa conscientização deve ter início na formação inicial do professor, na graduação.

\section{METODOLOGIA}

O método quantitativo foi usado para análise dos dados coletados por meio de questionário aplicado aos acadêmicos dos $1^{\text {os }}$ anos dos cursos de Letras/Espanhol e Letras/Inglês da Universidade Estadual do Norte do Paraná - UENP, Campus Jacarezinho.

O questionário constou de nove questões que investigaram as crenças e atitudes linguísticas dos acadêmicos dentre elas: i) a visão de ensino de língua portuguesa, ii) a principal tarefa do professor de língua portuguesa, iii) o principal conteúdo a ser ensinado nas aulas de LP; iv) se sabem o que é variação linguística, v) se têm preconceito linguístico, vi) se consideram importante a abordagem da variação linguística no contexto escolar.

Após a coleta dos dados, fizemos a descrição das respostas e tabulamo-nas em gráficos para melhor visualização dos resultados.

O total de graduandos dos $1^{\text {os }}$ anos dos cursos de Letras participantes da pesquisa foi de 54 alunos, 20 alunos da turma de Letras/Espanhol e 34 alunos da turma de 
Letras/Inglês. Vale mencionar que a turma de Letras/Espanhol era composta de 22 estudantes, porém dois estudantes não participaram da pesquisa, porque faltaram no dia.

No corpo do texto das análises quando fazemos referência ao discurso dos alunos, para preservar a identidade deles, usamos AE (Aluno de Espanhol).

Como nosso espaço é exíguo, exibimos a descrição e análise apenas das seis questões citadas.

\section{ANÁLISE DAS CRENÇAS E ATITUDES LINGUÍSTICAS DOS ACADÊMICOS DOS $1^{\text {os }}$ ANOS DOS CURSOS DE LETRAS}

A maioria dos graduandos, 22 deles, acredita que ensinar a gramática, a norma padrão, é a principal tarefa do professor de Língua Portuguesa, seguido de 11 graduandos que creem que é ensinar os usos da língua.

Gráfico 1: Respostas à questão 1

\begin{tabular}{|l} 
Questão 1 - Para você, qual é a principal tarefa do professor de \\
Língua Portuguesa? \\
\\
\end{tabular}

Fonte: Pinto (2018, p. 107)

O gráfico mostra, também, que 10 graduandos acreditam que a principal tarefa do professor de Língua Portuguesa é ser mediador de conhecimentos; cinco graduandos consideram dar aula como principal tarefa e quatro não responderam à pergunta.

Gráfico 2: Respostas à questão 2

Questão 2 - Qual o principal objetivo de fazer o curso de Letras?

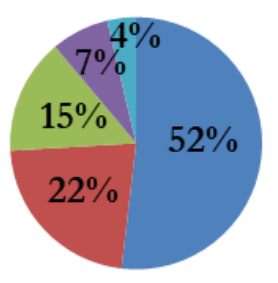

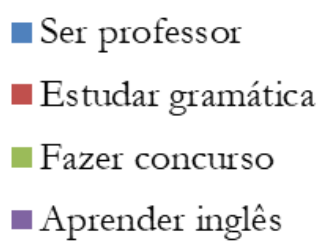

- Ser editor de livros e tradutor

Fonte: Pinto (2018, p. 108) 
Pelos dados do gráfico, é possível observar que a maioria dos graduandos, isto é, 28 deles, declararam que o principal objetivo pela escolha do curso de Letras é seguir a carreira docente. Além do mais, muitos responderam que querem ser um profissional que faz a diferença.

Já 12 acadêmicos mencionaram que optaram por fazer o curso de Letras para aprimorar seus conhecimentos em gramática e oito graduandos alegaram que, depois do curso concluído, pretendem fazer concurso ou outro vestibular.

Com esses objetivos, os acadêmicos demonstraram que a visão tradicional de ensino ainda prevalece entre eles, pois muitos veem, no curso de Letras, a oportunidade de aprender a gramática normativa, a língua como fim em si mesma, o que lhes dará suporte, conhecimento e aprendizado também para prestar concursos e vestibulares.

Outros quatro acadêmicos mencionaram que fazem o curso de Letras para aprender inglês, seguidos de dois acadêmicos que querem ser editores de livros e tradutores.

Diante disso, é possível observar que o objetivo maior da licenciatura, o de formar professores, não é o mesmo objetivo de muitos alunos. É possível notar, pelas respostas de vários graduandos, que eles não veem diferença entre ser professor e ser tradutor, por exemplo. Provavelmente avaliam que "[...] dominar a língua habilita um indivíduo a exercer ambas as profissões" (EMÍDIO, 2007, p. 71).

Gráfico 3: Respostas à questão 5

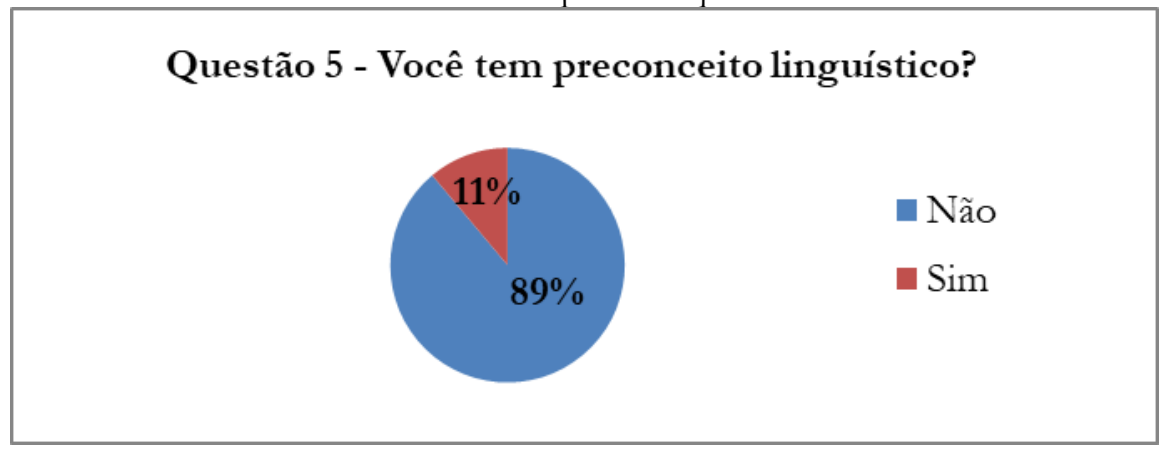

Fonte: Pinto (2018, p.111)

Majoritariamente, os dados do gráfico, resposta à pergunta da questão 5, revelam que os alunos dos $1^{\text {os }}$ anos dos cursos de Letras/Espanhol e Letras/Inglês não são preconceituosos.

Os 11\% dos acadêmicos que declararam que são preconceituosos, pelas respostas dadas, têm noção do que é preconceito linguístico. Não responderam aleatoriamente.

AE: "Sim. E descobri que tenho depois que comecei a fazer o curso de Letras, pois doem nos meus ouvidos ver pessoas falando errado: ponha, noi vai, pobrema".

AE: "Não posso dizer que não tenho, pois quando ouço pessoas falando errado, corrijo-as mentalmente. Sem contar que fico com vontade de dar risada".

Gráfico 4: Resposta à questão 7 


\section{Questão 7 - Qual(is) o(s) conteúdo(s) que você julga mais importante(s) no ensino de Língua Portuguesa?}

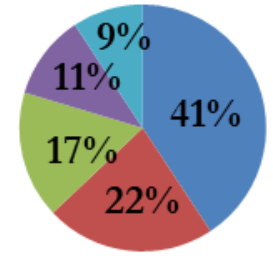

- Gramática

Literatura

Todos

- Gramática e Literatura

Redação

Fonte: Pinto (2018, p.113)

Os dados do gráfico 4 revelam que 22 graduandos consideraram o estudo da gramática o conteúdo mais importante no ensino de Língua Portuguesa, seguido de 12, que consideraram o conteúdo de Literatura e nove, que declararam que todos os conteúdos são importantes.

Em ordem decrescente, seis graduandos mencionaram mais de uma das opções apresentadas, considerando duas disciplinas de igual importância: Gramática e Literatura. Em seguida, cinco acadêmicos creem que é a prática da redação.

Os dados tabulados mostram que os acadêmicos ainda veem o ensino da gramática como o conteúdo mais importante a ser estudado nas aulas de Língua Portuguesa. Isso demonstra que eles têm uma concepção de ensino, conforme já mencionamos, com raízes na tradição normativa da língua, a qual, certamente, trazem do ensino básico.

Gráfico 5: Resposta à questão 8

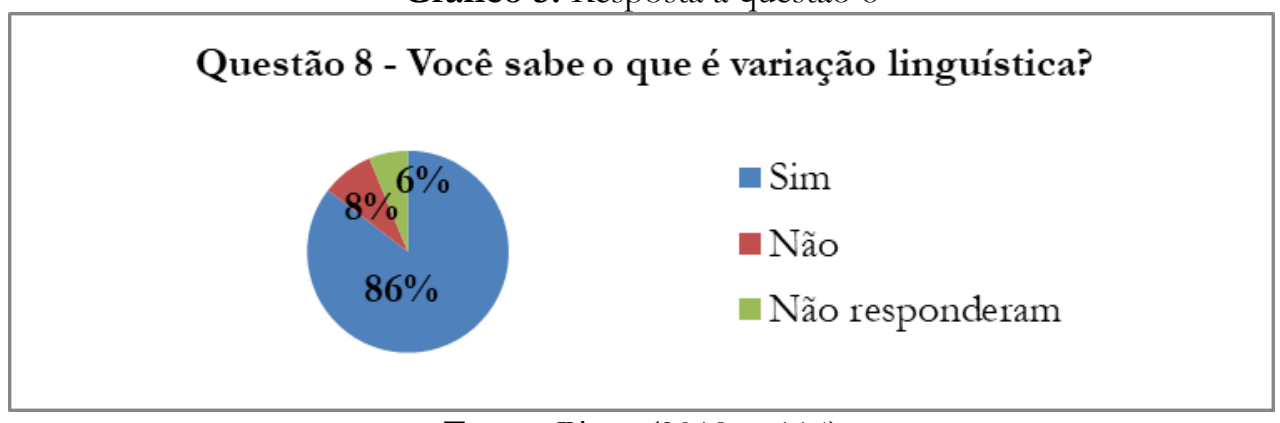

Fonte: Pinto (2018, p.114)

A questão 8 indaga se o acadêmico sabe o que é variação linguística. Em caso afirmativo, pedimos para justificar a resposta, explicando o conceito de variação linguística.

Os dados do gráfico 5 mostram que 41 calouros de Letras declararam saber o que é variação linguística; quatro calouros responderam que não sabiam o que era e três calouros deixaram de responder. 
De acordo com as respostas, observamos que os acadêmicos que disseram que sabiam o que é variação linguística têm visão de variação regional, ligada apenas à variação diatópica e à variação no nível lexical e no nível fonético-fonológico.

Acreditamos que essa visão seja também resultado da forma como viram a variação linguística no ensino básico: a abordagem da variação é feita, na maioria das vezes, em termos regionalistas. A variação não é vista como um fenômeno linguístico que apresenta sempre uma ou mais formas em concorrência, em todos os níveis gramaticais: lexical, fonológico, morfológico, sintático, semântico, discursivo.

Gráfico 6: Respostas à questão 9

\section{Questão 9 - Você considera importante que as variedades linguísticas sejam "ensinadas" na escola?}

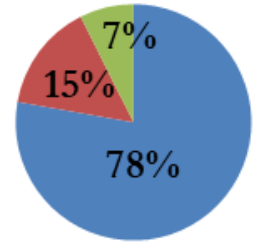

$\square \operatorname{Sim}$

- Não

Indecisos

Fonte: Pinto (2018, p. 115)

As respostas a essa última pergunta do questionário mostra, novamente, que a maioria dos acadêmicos considera importante que as variedades linguísticas sejam ensinadas na escola, contrapondo-se aos que rejeitam o ensino da variação linguística nas escolas e à minoria que se mostrou indecisa sobre essa questão.

Diante desses dados, é possível observar que os alunos, a maioria, são a favor da abordagem da variação linguística no contexto escolar, embora, pelas respostas dadas à questão anterior, essa maioria tenha uma visão estereotipada de variação, a variação voltada para o léxico e sotaques regionais, confirmada pelas respostas tanto dos que são favoráveis quanto dos que são contra a abordagem da variação nas salas de aula.

\section{RESULTADOS}

Por meio da análise dos dados, exibidos nos gráficos, no que diz respeito às crenças e atitudes dos acadêmicos dos $1^{\text {os }}$ anos dos cursos de Letras/Espanhol e Letras/Inglês da UENP/CJ, com relação à visão de ensino de língua portuguesa, podemos observar que quase a maioria crê que ensinar gramática é a principal tarefa de professor de língua portuguesa.

Também, a maioria deseja ser professor, por isso escolheu fazer o curso de Letras e declarou não ter preconceito linguístico. Essa crença se confirma pela resposta que os acadêmicos deram quando questionados sobre como reagiriam diante de um colega de turma que usasse, em sua fala, variantes estigmatizadas: a maioria dos graduandos 
respondeu que não corrigiria o colega, explicaria o que foi perguntado, mas nada falaria ao rapaz, e respeitaria seu modo de falar. Atitude considerada de valoração positiva com relação à língua do outro.

Esses estudantes dos $1^{\text {os }}$ anos dos cursos de Letras sabem o que é variação linguística, mesmo que esse conhecimento seja mais restrito à variação regional. Ademais são favoráveis ao "ensino" da variação linguística no contexto escolar, embora muitos tenham demonstrado que ainda estão apegados ao ensino da norma padrão, ao julgarem, como conteúdo mais importante no ensino da língua portuguesa, o estudo da gramática.

Diante desse resultado, podemos observar que a maioria dos acadêmicos ainda acredita na profissão de ensinar, sonha em ser professor, mesmo frente à baixa procura pelos cursos de licenciatura no país.

As crenças dos estudantes levam-nos a acreditar que eles trazem, da formação básica ${ }^{2}$, uma concepção de língua como expressão do pensamento, de língua como fim em si mesma, uma visão tradicional prescritivista, em que prevalece o "certo" e o "errado" para o uso da língua, seja escrita ou falada.

Diante disso, pretendemos contribuir para mudar essa realidade, levando para as salas de aula da formação docente inicial, proposta de Intervenção Pedagógica que prioriza a Sociolinguística Educacional e a pedagogia da Variação Linguística, com o objetivo de conscientizar os futuros docentes de Letras sobre a necessidade do reconhecimento da heterogeneidade linguística do Brasil e da importância do trabalho sobre e como lidar com a variação linguística no contexto escolar da educação básica.

Santos (1996, p. 15) afirma que as atitudes de uma pessoa são movidas por suas crenças, portanto, pretendemos fazer valer a assertiva do autor: "[...] a atitude de um indivíduo pode ser mudada, se forem mudadas suas crenças sobre o objeto”.

Sobre o pensamento de Santos, reafirmamos as palavras de Almeida Baronas e Marques (2015, s.p.), com as quais concordamos plenamente, ao mencionarem que a assertiva de Santos alcança sua importância, uma vez que devemos acreditar que "[...] é necessário fomentar crenças positivas nos alunos sobre a variação linguística, para que a atitude com relação à sua língua seja positiva e a escola cumpra seu papel e forme cidadãos capazes de utilizar adequadamente sua língua".

\section{CONSIDERAÇÕES FINAIS}

Mattos e Silva (2004, p. 34-35) explicita que deveria competir à escola, desde o préescolar, orientar uma programação que visasse, com prioridade, desenvolver a potencialidade expressiva do sujeito-aluno, a partir da experiência anterior à escola e com vistas a que, ao fim do transcurso escolar, fosse ele capaz de dominar as variedades disponíveis da língua em sua expressão, estando entre elas a chamada "língua de cultura", na forma falada ou escrita.

\footnotetext{
2 O questionário que investigou o perfil sociolinguístico dos alunos dos 1 os anos de Letras/Espanhol e Letras/Inglês mostrou que a maioria dos alunos que ingressa no curso de Letras fez o ensino fundamental e médio em escolas públicas e não fez curso pré-vestibular para prestarem o vestibular de Letras.
} 
Conforme Bezerra (2017), versando sobre a língua e fenômenos linguísticos, o fim da ignorância sobre a língua, acompanhado do fim do preconceito linguístico e da exclusão pela linguagem, só pode ser atingido por meio do ensino esclarecido e esclarecedor, ou pelo menos este parece ser o caminho mais eficaz. Há uma necessidade urgente, para isso, de superação da discrepância entre as relativamente avançadas premissas estabelecidas pelas diretrizes oficiais de ensino e as práticas efetivas de ensino de língua portuguesa.

De acordo com essas diretrizes, “[...] é preciso, essencialmente, ensinar língua portuguesa a partir de textos produzidos em situações reais de uso, em diferentes gêneros, e contemplando as diversas variedades sociais da língua, e não apenas a norma estabelecida como padrão pela e para a elite brasileira" (BEZERRA, 2017, p. 07, grifos do autor).

Portanto o ensino da Língua Portuguesa deve levar em consideração as variedades linguísticas dos alunos, sejam elas estigmatizadas ou não, concomitante ao ensino da norma padrão, para que assim haja uma verdadeira transformação na vida do aluno através da educação, tornando-o um cidadão crítico ciente dos seus direitos e deveres.

Por meio do nosso estudo, observamos que, na década de 1980, já se reconhecia, mas não se levava em consideração a diversidade linguística em nosso país. A escola tratava a língua de forma homogeneizante e o ensino da LP de modo prescritivista.

Já, nos documentos oficiais de ensino atuais, o tema variação linguística é preconizado. Assim, escola e sociedade não podem deixar de reconhecer as variedades linguísticas quaisquer que sejam, bem como não podem negar ou dificultar o acesso dos alunos ao domínio das variedades linguísticas que ele desconhece.

Para que isso aconteça, postula Cyranka (2014) que a formação sociolinguística do professor deve ter início na graduação, durante o curso de Letras, para que possam construir uma consciência linguística sobre a importância da abordagem da variação linguística nas aulas de LP.

Conforme os resultados apontados pela pesquisa que fizemos com os estudantes que ingressam nos cursos de Letras da UENP/CJ, por meio de aplicação de questionário, observamos que eles chegam aos cursos com uma visão voltada para o ensino prescritivo, para o ensino tradicional de gramática, têm conhecimento sobre variação linguística, mas é um conhecimento estreito, voltado para as variedades regionais apenas. Sabemos, entretanto, que a variação linguística acontece em todos os níveis da língua: fonéticofonológico, morfológico, sintático, lexical, semântico e discursivo.

Portanto, diante da heterogeneidade linguística que nos cerca, é preciso que os professores e os futuros professores, principalmente os de Língua Portuguesa, tenham o conhecimento sobre os pressupostos básicos da Sociolinguística Educacional e saibam como desenvolver uma pedagogia da variação linguística, uma pedagogia culturalmente sensivel nas salas de aula.

\section{REFERÊNCIAS}


AGUILERA, V. de A.. Crenças e atitudes lingüísticas: o que dizem os falantes das capitais brasileiras. In: Estudos lingüísticos, São Paulo, 37 (2): 105-112, mai-ago. 2008. Disponível em: <http://www.gel.org.br/estudoslinguisticos/volumes/37/ EL_V37N2_11.pdf>. Acesso em: 29 ago. 2017.

ALMEIDA BARONAS, J. E.; MARQUES, T. M.. Crenças e atitudes linguísticas na sala de aula. In: Linguasagem (São Paulo), v. 24, p. 154-387, 2015. Disponível em: <http://www.linguasagem. ufscar.br/index.php/ linguasagem/article/view/154/127>. Acesso em: 15 jul. 2016.

BAGNO, M.. A língua de Eulália: novela sociolinguística. São Paulo: Contexto, 2008.

BARCELOS, A. M. F.. Cognição de professores e alunos: tendências recentes na pesquisa de crenças sobre ensino e aprendizagem de línguas. In: Crenças e Ensino de Linguas: Foco no professor, no aluno e na formação de professores. Campinas, SP: Pontes Editores, 2006.

BEZERRA, B. G.. Precisamos de professores (bem) formados em Letras? In: Informativo Parábola Editorial. São Paulo. Ano XVI. 2017. $\sigma^{\text {a }}$ edição.

BORTONI-RICARDO, S. M.. Educação em lingua materna: a sociolinguística na sala de aula. São Paulo: Parábola Editorial, 2004.

BORTONI-RICARDO, S. M.. Análise e diagnose de erros no ensino da língua materna. In: BORTONI-RICARDO, S. M.. Nós cheguemu na escola, e agora? Sociolinguística e educação. São Paulo: Parábola, 2005. p. 53-59.

BORTONI-RICARDO, S.M. Subsídios da Sociolinguística educacional. In: Revista Educação, publicação especial no 2. São Paulo: Editora Segmento, 2010.

BORTONI-RICARDO, S. M.. Contribuições da Sociolinguística Educacional para o processo ensino e aprendizagem da linguagem. Disponível em: $<$ www.stellabortoni.com.br/index.php/artigos/707-iootaibuicois-ia-soiiolioguistiiaiiuiaiiooal-paaa-o-paoiisso-iosioo-i-apaioiizagim-ia-lioguagim>. Acesso em: 13 set. 2016.

BORTONI-RICARDO, S. M.; FREITAS, V. A. de L.. Sociolinguística Educacional. In: HORA, D. da; et al (orgs.) Abralin: 40 anos em cena. João Pessoa: Editora Universitária, 2009.

BRASIL. SECRETARIA DE EDUCAÇÃO FUNDAMENTAL. Parâmetros curriculares nacionais: terceiro e quarto ciclos do ensino fundamental: língua portuguesa. Brasília: MEC/ SEF, $1998 . \quad$ Disponível em: <http://portal.mec. gov.br/seb/arquivos/pdf/portugues.pdf>. Acesso em: 30 out. 2014.

CARRARO, F. P.. Crenças e atitudes linguísticas: um estudo sobre a língua espanhola como língua estrangeira. Universidade Estadual do Centro-Oeste - UNICENTRO, Guarapuava, 2016. Dissertação de Mestrado. Disponível em: <https://www.academia.edu/28650515/ 
Cren $\%$ C3\%A7as_e_Atitudes_Lingu $\%$ C3\%ADsticas_um_estudo_sobre_a_1\%C3\%ADn gua_espanhola_como_1\%C3\%ADngua_estrangeira $>$. Acesso em: 15 abr. 2016.

COELHO, I. L.; et al. Sociolinguística. Florianópolis: LLV/CCE/UFSC, 2010. Disponível em: <http://ppglin.posgrad.ufsc.br/files/2013/04/Sociolingu\%C3\%ADstica _UFSC .pdf>. Acesso em: 27 out. 2014.

CORBARI, C. C.. Crenças e Atitudes Linguísticas de Falantes de Irati (PR). Signum: Estud. Ling. $\mathrm{n}^{\mathrm{o}} 15 / 1$, p. 11-127, Londrina: 2012. Disponível em: <http://www.uel.br/revistas/uel/index.php/signum/article/view/11378/11173>. Acesso em: 20 mai. 2017.

CYRANKA, L. F. de M.. Atitudes lingüísticas de alunos de escolas públicas de Juiz de Fora. - MG. 2007. 174 f. Universidade Federal Fluminense, Niterói, 2007. Tese de Doutorado. Disponível em: <http://www.bdtd.ndc.uff.br/tde_arquivos/23/TDE-2007-1022T153843Z-1058/Publico/ Tese-Lucia\%20Cyranka.pdf>. Acesso em: 20 mai. 2015.

CYRANKA, L. F. de M.. Avaliação das variantes: atitudes e crenças em sala de aula. In: MARTINS, M. A.; VIEIRA, S. R.; TAVARES, M. A.. (Orgs). Ensino de português e sociolinguística. São Paulo: Contexto, 2014.

CYRANKA, L. F. de M.; et al. Variação linguística na escola: desafios e possibilidades. In: Interdisciplinar. Ano IX, jan./jun. 2014. Itabaiana/SE. p. 73-94. Disponível em: <https://seer.ufs.br/index.php/ interdisciplinar/article/view/2859/2549>. Acesso em: 20 mai. 2016. Tem que ver qual aparece primeiro pra colocar a e b

CYRANKA, L. F. de M.. A pedagogia da varição lingüística é possível? In: ZILLES, A. M. S.; FARACO, C. A.. Pedagogia da variação linguística: língua, diversidade e ensino. São Paulo: Parábola Editorial, 2015. p. 31-51.

CYRANKA, L. F. de M.. Sociolinguística aplicada à educação. In: MOLLICA, M. C.; FERRAREZI JUNIOR, C.. (Org.). Sociolinguistica, Sociolinguísticas. São Paulo: Editora Contexto, 2016.

DIAS, P. M. C. R.. Contribuições da sociolinguística educacional para materiais de formação continuada de professores de lingua portuguesa. 2011. 323 f. Tese (Doutorado em Linguística) Universidade de Brasília, Brasília, 2011.

EMIDIO, D. E.. Processo de conscientização do futuro professor de língua inglesa sobre as especificidades de se aprender inglês para ensinar. 2007. 126 f. Dissertação (Mestrado) -Universidade Federal de São Carlos, UFSCar, São Carlos, 2007. Disponível em: <http://www.ufscar.br/ ppgl/defesas/ 012.pdf>. Acesso em: 20 set. 2017.

ERICKSON, F. Transformation and School Success: the Politics and Culture of Educational Achievement. In: Anthropology \& Education Quartely. Vol. 18, n. 4, 1987.

FARACO, C. A.. Norma culta brasileira: construção e ensino. In: ZILLES, A. M. S.; FARACO, C. A.. Pedagogia da variação linguística: língua, diversidade e ensino. São Paulo: Parábola Editorial, 2015. P.19-29. 
FARACO, C. A.. História sociopolítica da língua portuguesa. 1. ed. São Paulo: Parábola Editorial, 2016.

FARACO, L. C.; ZILLES, A. M. S.. Pedagogia da variação linguística. São Paulo: Parábola Editorial, 2015.

GÓMEZ MOLINA, J. R.. Actitudes lingüísticas en una comunidad bilíngüe y multidialectal: area metropolitana de Valencia. Anejo n. XXVIII dela Revista Cuadernos de Filología. Valencia, Universitat de Valencia, 1987.

LABOV, W.. Sociolinguistic Patterns. Pennsylvania: University of Pennsylvania Press, 1972.

LABOV, W.. Padrões Sociolinguísticos. Trad.: Marcos Bagno; Marta Scherre e Caroline Cardoso. São Paulo: Parábola, 2008.

LAMBERT, W. E.. A Social Psychology of Bilingualism. [1967] In: PAULSTON, C. B.; TUCKER, G. R. (orgs.). Sociolinguistics: the essential readings. Malden, MA: Blackwell Publishing, 2003.

LAMBERT, W. W.; LAMBERT, W. E.. Psicologia Social. Rio de Janeiro: Zahar editores, 4 ed. 1972. Tradução de Dante Moreira Leite.

LIBÂNEO, J. C.. Pedagogia e pedagogos: para quê? São Paulo: Cortez, 1998.

MATTOS E SILVA, R. V.. Diversidade linguística, língua de cultura e ensino de português. In: O português são dois: novas fronteiras, velhos problemas. São Paulo: Parábola, 2004. p. 27-36.

MONTEIRO, J. L.. Para compreender Labov. Petrópolis: Vozes, 2000.

PINTO, V. M. R.. Por uma educação eociolinguística consciente nos cursos de Letras. 2018. 251 f. Tese (Doutorado em Estudos da Linguagem) - Universidade Estadual de Londrina, Londrina, 2018.

SANTOS, E.. Certo ou errado? atitudes e crenças no ensino da língua portuguesa. Rio de Janeiro: Graphia, 1996.

SILVA, F. B.; BOTASSINI, J. O. M.. Crenças e Atitudes Linguísticas: o que pensam os alunos de Letras sobre o ensino de Língua Portuguesa. In: Letras \& Letras (Online), v. 31/2, 2015.2 Disponível em: <http://www.seer.ufu.br/index.php/letraseletras/article/view/31457>. Acesso em: 05 set. 2017.

Recebido em: $17 / 05 / 2018$

Aprovado em: 06/10/2018

Publicado em: 31/12/2018 